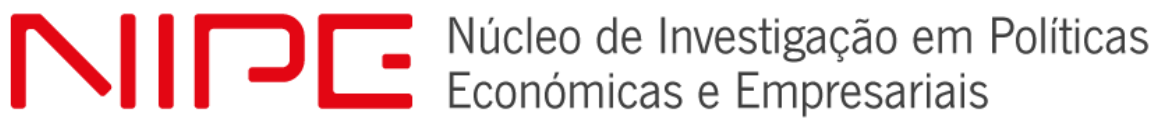

\section{WORKING PAPER}

Fernando Alexandre

Sara Cruz

Miguel Portela

\section{"Financial distress and the role of management in micro and small-sized firms"}

https://www.eeg.uminho.pt/pt/investigar/nipe

\section{FCT}

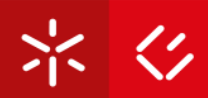




\title{
Financial distress and the role of management in
}

\section{micro and small-sized firms*}

\author{
Fernando Alexandreł Sara Cruz ${ }^{\ddagger}$ and Miguel Portela ${ }^{\S}$
}

October 6, 2020

\begin{abstract}
In this paper, we focus on managerial characteristics of micro and small-sized firms. Using linked employer-employee data on the Portuguese economy for the 2010-2018 period, we estimate the impact of management teams' human capital on the probability of firms becoming financially distressed and on their subsequent recovery. Our estimates show that the relevance of management teams' formal education on the probability of firms becoming financially distressed depends on firms' size and the type of education. We show that management teams' formal education and tenure reduces the probability of micro and small-sized firms becoming financially distressed and increases the probability of their subsequent recovery. The estimates also suggest that those impacts are stronger for micro and small-sized firms. Additionally, our results show that functional experience previously acquired in other firms, namely in foreign-owned and in exporting firms and in the area of finance, may reduce the probability of micro firms becoming financially distressed. On the other hand, previous functional experience in other firms seems to have a strong and highly significant impact on increasing the odds of recovery of financially distressed firms. We conclude that policies that induce an improvement in the managerial human capital of micro and small-sized firms have significant scope to improve their financial condition, enhancing the resilience of the economy against shocks.
\end{abstract}

Keywords: Financial distress; human capital; firm performance.

JEL Classification: G32, J24, L25

*This paper is financed by National Funds of the FCT - Portuguese Foundation for Science and Technology, projects UIDB/03182/2020 and PTDC/EGE-ECO/29822/2017 ("It's All About Productivity: contributions to the understanding of the sluggish performance of the Portuguese economy").

${ }^{\dagger}$ Universidade do Minho, NIPE, falex@eeg.uminho.pt.

$\ddagger$ Universidade do Minho, NIPE, saracruz@eeg.uminho.pt.

$\S$ Corresponding author: Universidade do Minho, NIPE \& IZA, Bonn, miguel.portela@eeg.uminho.pt. 


\section{Introduction}

This paper adds to an increasing body of research that relates firms' management factors with the financial condition and overall performance of firms (e.g., Bloom et al., 2016; Darrat et al., 2016; Huang and Hilary, 2018; Mion and Opromolla, 2014; Sazedj et al., 2018). Using unique and rich linked employer-employee data, we contribute to a better understanding of the role of management teams' human capital in the financial condition of micro and small-size firms.

Micro and small-sized firms are pervasive in the business structure of the Portuguese economy. In 2018, firms under 50 workers account for $98,8 \%$ of total firms, $57,5 \%$ of total employment and 50,3\% of total value-added. However, micro firms show very low productivity levels, corresponding to $60 \%$ and $56 \%$ of the productivity of medium and large firms, respectively, in 2018 - see Table A1. A high share of micro and smallsized firms has been related to resource misallocation and low productivity growth (e.g., Garicano et al., 2016). Management is crucial for firms' financial and operational performance (e.g., Bloom and Van Reenen, 2007). However, most of the studies on the impact of management in firms' performance have been based on case studies and surveys (e.g., Bloom and Van Reenen, 2010). Those approaches have focused on medium and large-sized firms, being less effective in dealing with micro and small-sized firms. The availability of firm-level data for the Portuguese population of firms, including detailed information on the characteristics of management teams' members and the balance sheet and financial statement of firms, allows us to investigate the role of management teams' on micro and small firms' financial condition.

During the international financial crisis of 2008/2009 and the sovereign debt crisis in the euro area in the period 2010/2013, the Portuguese economy went through a severe crisis. Between 2008 and 2013: real GDP decreased by 8\%; employment decreased $13 \%$ and unemployment increased from $7.7 \%$ to $16.4 \%$ (INE, Statistics Portugal). The Portuguese crisis was a debt and a banking crisis. The total debt of non-financial firms, relative to GDP, reached a maximum of $152 \%$ in 2012 , one of the highest in the world (data from the Bank of Portugal). A large share of firms was highly leveraged and unprofitable. In 2013, 34\% of the firms had a negative EBITDA (Earnings Before Interest, Taxes, Depreciation, and Amortization) and the average EBITDA to Operating 
Revenue ratio across all firms in the economy was $-15.5 \%$ (data from SCIE, INE; further details on data in subsection 2.1). Therefore, during the economic and financial crisis a high share of firms was financially distressed - see Gouveia et al. (2018) and Carreira and Teixeira (2016).

Firms' financial distress, often associated with high leverage and lower performance, has constituted a relevant branch of financial and macroeconomic literature that is recalled to unveil countries' productivity issues and hurdles in national economic growth (e.g., Andrews and Petroulakis, 2019). Authors state that the steady survival of financially distressed firms, commonly called zombie firms, act as distorting forces behind aggregate capital allocation, given that their increasing maintenance by creditors' forbearance yields credit congestion to more productive firms, hampers market competition, and ultimately leads to decreases in national aggregate productivity growth (e.g., Caballero et al., 2008; Andrews et al., 2017; Andrews and Petroulakis, 2019).

Several factors have contributed to a high and persistent incidence of financially distressed firms: banks' evergreen lending to inefficient firms (e.g., Caballero et al., 2008; Fukuda and Nakamura, 2011; Acharya et al., 2019; Andrews and Petroulakis, 2019); high leverage and credit constraints (e.g., Schivardi et al., 2017); credit misallocation due to underdeveloped financial markets (e.g., Reis, 2013; Gopinath et al., 2017; Azevedo et al., 2018); and inefficient insolvency regimes (e.g., Andrews et al., 2017). This paper contributes to this literature by exploring the role of management teams' characteristics to the probability of firms becoming financially distressed and to their subsequent recovery.

Nicholas Bloom, John Van Reenen and their co-authors have concluded that firms with 'better' management practices tend to be larger, to be more efficient, to grow faster, and to have higher survival rates (e.g., Bloom and Van Reenen, 2007; Bloom et al., 2013). Additionally, those authors also conclude that firms with more human capital tend to have better management practices. Firms' management teams are empowered with decisional ability and executive power which directly affects their productivity, performance and their financial prospects (e.g., Boone et al., 2007; Darrat et al., 2016; Huang and Hilary, 2018; Chen et al., 2010; Lin and Lin, 2019). Managerial human capital can be defined as the stock of routines, skills and knowledge embedded in the governance structure, composed by individuals endowed with decisional and 
executive competencies that directly affect the organizational performance (e.g., Roos et al., 1997). Human capital comprises both formal and tacit knowledge relevant to economic activities. Hence, firms' management boards human capital embody a varied set of skills acquired through formal education and informal tacit components, that are path-dependent such as training and experience, accumulated both transversally and within the industry, which literature has proven to be crucial on firms' performance (e.g., Bloom and Van Reenen, 2010).

In our analysis, we consider three dimensions of management teams' human capital. First, managers' formal education, measured by average years of schooling, the inclusion in the management team of at least one manager with a college degree, and the share of the management team with a college degree. Second, within-firm specific knowledge proxied by managers' tenure. Third, we consider four dimensions of functional experience formerly acquired in other firms: years of management experience in other firms; previous experience in the area of finance; previous experience in international firms; and previous experience in former exporting firms.

Education levels of the workforce and management teams have increased significantly in the last decades, reducing the gap to European Union countries - see Almeida et al. (2017). As noticed by Bloom and Van Reenen (2010), there is evidence of a positive relationship between education and the quality of management practices. Management teams that include members with a college degree are expected to make use of state of the art management practices, namely the use of information and communication technologies. The role of education is even more important for micro and small-sized firms, where in most cases ownership and management coincide and firms have scarce resources to hire new members to the management teams. Therefore, in our analysis, we evaluate the impact of years of schooling and of having members in the management team with a college degree.

Our second measure of human capital is within-firm specific knowledge. The evidence on the benefits of a long-tenured management team is mixed. Li (2018) and Huang and Hilary (2018) conclude that managers' tenure and their firm-specific knowledge affect companies' overall performance according to their entrenchment level, with positive learning effects up to an optimal threshold. A longer tenure results in a deep knowledge of the firm and of its culture which improves communication and decisional 
processes. On the other hand, a long experience in the firm may reduce their openness to innovation. Given the high coincidence of ownership and management, tenure in micro and small-sized firms tends to be higher than in larger firms.

Expertise and knowledge spillovers from managers' mobility (e.g., Mion and Opromolla, 2014; Mion et al., 2016; Sazedj et al., 2018), appear to have significant effect on firms' overall and financial performance. In our analysis, we evaluate the impact of previous functional experience acquired in other firms. We consider the overall experience in other firms, previous experience in foreign-owned and exporting firms, and previous experience in finance. Bloom and Van Reenen (2010) stresses that multinationals are better managed than domestic firms. Those authors also stress that exporting firms are also better managed than firms that only produce for the domestic market. Mion et al. (2016) infer that knowledge and experience brought by outsider managers may have a significant effect on firms' performance. Mion and Opromolla (2014) undertake a track over years of the employees' mobility on their manager status at each period in the current firm, accounting for the previous export-based and matching exportation experience, concluding for the positive impact of managerial aspects, such as exportmatching knowledge on firm trade performance. Sazedj et al. (2018) assess the impact of newly recruited versus internally experienced CEOs on firms' performance, during the economic crisis, providing evidence that new knowledge and experience brought by outsider CEOs have a significant effect on firms' productivity and on their capability to survive under negative economic shocks. Functional experience in the area of finance was also found to be relevant to firms' financial policies (e.g., Custódio and Metzger, 2014).

The remainder of this paper is organized as follows. Section 2 describes the databases and variables and shows the statistics for our empirical measures of managerial human capital. Section 3 presents the econometric strategy. Section 4 presents and discusses the estimation results. Section 5 concludes.

\section{Data, variables and descriptive statistics}

This section presents the databases and variables used in our empirical analysis and describes their descriptive statistics, stressing their differences across firm-size classes. 


\subsection{Linked employer-employee data}

In this paper, we use linked employer-employee data to characterize managerial features of Portuguese firms, to contribute to a better understanding of the role of management teams in micro and small-sized firms' financial condition. The analysis of management teams' characteristics based on microdata allows for a richer overview of their role in micro and small-sized firms' performance. Our approach, using linked employeremployee data, in the vein of Mion and Opromolla (2014), complements the research carried out by case studies and surveys (e.g., Bloom and Van Reenen, 2010).

We use panel data drawn for the period 2008-2018 for the Portuguese economy, from two main datasets: Personnel Records database (QP, 'Quadros de Pessoal', INE, 2018a) on workers and the Integrated Business Accounts System (SCIE, 'Sistema de Contas Integradas das Empresas', INE, 2018b) from Statistics Portugal's Registry of Statistical Units at the firm level. QP is a unique matched employer-employee dataset collected by the Portuguese Ministry of Labour, Solidarity and Social Security, integrating yearly data of all private firms, respective establishments and employees in Portugal, since 1986. It is disaggregated at the worker level, with a detailed track of each employee (gender, age, tenure, educational level, monthly earnings, hours worked, occupation, contract bond) and corresponding firm (location, industry sector, ownership structure, creation date) over time. This dataset includes highly representative data of the national labour market, with approximately 3,000,000 workers and 350,000 firms yearly.

SCIE involves all reported details on firms' balance sheet and their financial statement, required by governmental authorities yearly, and covers all non-financial firms from 2006 onwards (about 350,000 firms, yearly). This dataset presents enriching information at the firm level on economic and financial indicators, which allows us to obtain all the information on firms' capital structure and financial performance.

Our econometric analysis will cover the period that encompasses the international financial crisis of 2008/2009 and the euro area sovereign debt crisis of 2010-2013 and the economic recovery that followed. We focus on firms with a continuous record on our databases and ten or more years old at the beginning of our panel. ${ }^{1}$

\footnotetext{
${ }^{1}$ Data on years 2008 and 2009 was exclusively used as lagged information to classify all financially distressed firms over the period 2010-2018. 2018 is the latest year available at the time this study was carried out.
} 
Firms' organisation complexity and management structure varies significantly according to size (e.g., Lucas, 1978; Garicano et al., 2016). In our analysis we will show the results for the whole sample and by firm size, focusing on micro and small-sized firms. We consider the following four firm-size classes: Micro which includes firms with up to 9 workers; Small which includes firms with a workforce between 10 and 49 workers; Medium which includes firms between 50 up to 249 workers; and Large including firms with 250 workers or more. Table A1 in the Appendix presents detailed data for those four size classes of the population of Portuguese firms.

\subsection{Management and financial variables}

This paper contributes to the literature on the determinants of firms' financial distress.

We investigate the role of management teams' characteristics on the probability of firms becoming financially distressed and on their subsequent recovery. Our definition of financially distressed firms (henceforth, FDF) follows the OECD approach presented in McGowan et al. (2017). FDF show an Interest Coverage Ratio (ICR) - given by the ratio of EBITDA to interest expenses - inferior to one, over three consecutive years. The 3-year period on assessing the state of financial distress allows for accommodating economic downturns and temporary business decline (Gouveia et al., 2018). We only consider firms that are at least ten years old to avoid equivocal grading of start-up companies as financially distressed firms.

FDF and their weight in the economy significantly increased during the sovereign debt crisis, between 2010 and 2013. In 2012, the share of FDF in total firms reached a peak of $15.1 \%, 19.8 \%$ of total employment and $11.8 \%$ of total value-added. The economic recovery after 2013 led to a decreasing relevance of FDF, in a similar trend to other southern European countries (McGowan et al., 2017; Gouveia et al., 2018; Andrews et al., 2017). However, in 2018, FDF still accounted for $4.4 \%$ of total firms, $9.9 \%$ of total employment and $6.3 \%$ of total value-added. Financial distress prevails among micro and small-sized firms: in 2012, FDF represented in these size categories 93.6\% of total FDF, $29.8 \%$ of FDF employment, and $20.8 \%$ of total value-added in FDF. Still with considerable weight in 2018, micro and small-sized financially distressed firms constituted $87.8 \%$ of total FDF, $12 \%$ of FDF employment and $9.1 \%$ of FDF total value- 
added.

Once the ICR is bigger than one for two consecutive years we classify the firm as recovered from its condition of financial distress (Recovered) - see Table 1. Using that definition, Table A3 in the Appendix, presents the data with the evolution of recovered and non-recovered firms. In the period 2011-2017, the share recovered financially distressed firms increased continuously from $7.8 \%$ to $66.1 \%$, reflecting the economic recovery started in 2013 .

Our linked employer-employee databases, covering the population of firms in the Portuguese economy, allow us to identify the management teams and to describe several dimensions of managers' characteristics and expertise. Our data include information on managers' education, tenure and age. We also have the information for the whole life professional experience of managers, namely the industry they have worked or whether they have had professional experience in a firm involved in international trade or with a share of foreign capital.

Executive decisions which ultimately affect firms' capital and labour structure are held not only by the general manager but by a group of upper tiers such as high-level directors or key senior managers reporting to the administration board (Carpenter, 2002). This perspective suggests that even though the strict executive power is entailed by the CEO, there is a frequent decision-making process shared with an influential management team (Hambrick and Mason, 1984). In this vein, the variable Manager has been constructed by selecting all top managers, namely CEOs and executive directors, plus all firms' highest-level department directors, according to QP dataset classification. Using the CPP2010 national classification of occupations ${ }^{2}$ for the period after 2009 and CNP94 $^{3}$ for the period before 2010, occupational codes in this definition correspond to four and two categories, respectively. In the CPP2010 national classification of occupations, we consider as members of the management team: Managing Directors and Chief Executives (112); Administrative and Commercial Managers (12); Production and Specialized Services Managers (13); and Hospitality, Retail and Other Services Managers (14). In CNP94 national classification of occupations, we consider as members of the management team: Corporate Managers (12); and General Managers of Small

\footnotetext{
${ }^{2}$ Classificação Portuguesa das Profissões 2010 - CPP 2010, Statistics Portugal, corresponding to ISCO-08 international nomenclature.

${ }^{3}$ Classificação Nacional das Profissões CNP/94, Statistics Portugal.
} 
Table 1: Variable description and sources

\begin{tabular}{|c|c|c|}
\hline Variable & Description & Source \\
\hline Financially Distressed Firm (FDF) & $\begin{array}{l}\text { FDF }=1 \text { if financially distressed; } 0 \text { otherwise. } \\
\text { FDF has been defined as having an interest cov- } \\
\text { erage ratio inferior to one over three consecutive } \\
\text { years. }\end{array}$ & SCIE \\
\hline Recovered Financially Distressed Firm & $\begin{array}{l}\text { Recovered }=1 \text { if the firm recovered from the finan- } \\
\text { cially distressed status; } 0 \text { otherwise. Recovered } \\
\text { firm is defined as being in a non-FDF state over } \\
\text { two consecutive years. }\end{array}$ & SCIE \\
\hline Managers' age & AgeManager $=$ managers' average age & QP \\
\hline Managers' education & $\begin{array}{l}\text { EducManager }=\text { managers' average years of } \\
\text { schooling }\end{array}$ & $\mathrm{QP}$ \\
\hline Manager with a college degree & $\begin{array}{l}\text { CollegeManager }=1 \text { if at least one manager has a } \\
\text { college degree; } 0 \text { otherwise }\end{array}$ & QP \\
\hline Share of managers with a college degree & $\begin{array}{l}\text { ShareCollegeManager = share of managers with a } \\
\text { college degree }(\%)\end{array}$ & $\mathrm{QP}$ \\
\hline Managers' tenure & $\begin{array}{l}\text { TenureManager = managers' average years in the } \\
\text { firm }\end{array}$ & $\mathrm{QP}$ \\
\hline Managers' experience & $\begin{array}{l}\text { ExpManager = managers' average years of experi- } \\
\text { ence in former firms }\end{array}$ & $\mathrm{QP}$ \\
\hline Managers' experience in finance & $\begin{array}{l}\text { FinExpManager }=\text { managers' average years of } \\
\text { overall finance experience in former firms }\end{array}$ & $\mathrm{QP}$ \\
\hline $\begin{array}{l}\text { Managers' experience in foreign- } \\
\text { owned/ international firms }\end{array}$ & $\begin{array}{l}\text { IntExpManager = managers' average years of ex- } \\
\text { perience in former international firms }\end{array}$ & QP \\
\hline $\begin{array}{l}\text { Managers' experience in exporting } \\
\text { firms }\end{array}$ & $\begin{array}{l}\text { ExportExpManager = managers' average years of } \\
\text { experience in former exporting firms }\end{array}$ & $\mathrm{QP}$ \\
\hline Leverage Ratio & $\begin{array}{l}\text { LevRatio = Total Liabilities/Total Equity and Li- } \\
\text { abilities }\end{array}$ & SCIE \\
\hline Productivity per worker & $\begin{array}{l}\text { Productivity }=\text { Gross Value-Added at cost of fac- } \\
\text { tors }(/ 1000 \text { euros }) / \text { Total Workers }\end{array}$ & SCIE \\
\hline Exports ratio & $\begin{array}{l}\text { ExportsRatio }=\text { Total Exports/Total Sales } \\
\text { Turnover }\end{array}$ & SCIE \\
\hline TeamManagerSize & Number of individuals in the management team & $\mathrm{QP}$ \\
\hline NWorkers & Number of workers by each firm & SCIE \\
\hline
\end{tabular}

Businesses (13).

All firms in our longitudinal panel have at least one top or department manager in their directorate boards. Our sample is fairly representative. In 2018, firms with a corporate society status with at least one manager represent about $25 \%$ of all the companies with at least 2 workers in the SCIE dataset and account for $68 \%$ percent of employment and $70 \%$ of value-added of all economic activities, except the primary sector. In this sample, firms aged as ten or more years with at least one manager and a continuous non-intermittent record over the panel represent approximately $28 \%$ of all firms with at least one manager, and account for $68 \%$ of value-added and $60 \%$ of total employment of firms with at least one manager, respectively $48 \%$ of total value-added 
and $41 \%$ of total employment of all SCIE firms dataset.

In our empirical analysis, managerial human capital variables include three categories: formal knowledge, given by the education of the members of the management team; tacit firm-specific knowledge, given by tenure; and tacit non-firm specific knowledge, given by functional experience previously acquired in other firms - see Table 1 for a description of these variables.

As mentioned in Bloom and Van Reenen (2010), education is highly correlated with management scores. Therefore, we expect more educated managers to have a better management performance, namely on the financial dimension. In our empirical analysis we consider three measures of formal education: i) managers' average years of schooling, EducManager; ii) a dummy variable that takes the value 1 if at least one manager has a college degree, CollegeManager; iii) share of managers with a college degree, ShareCollegeManager, which proxies the degree of homogeneity within the management team.

Tacit firm-specific knowledge is measured by the average years of tenure of the management board, TenureManager. As discussed in the previous section, the evidence concerning the impact of firm-specific knowledge on firms' performance is mixed (e.g., Huang and Hilary, 2018).

Non-firm specific tacit knowledge is gauged by four proxies of managerial functional background. Management overall experience, ExpManager, given by the average years of management experience that the members of the management team have accumulated in former firms. Finance overall experience, FinExpManager, as the average years acquired in former firms in a finance intermediate or senior position. In the QP dataset those positions correspond to the following occupational CPP2010/ ISCO-08 codes: 1211 - Finance Managers; 1346 - Financial and Insurance Services Branch Managers; 241 - Finance Professionals; 331 - Financial and Actuarial Associate Professionals. This variable intends to capture the accumulated experience in finance positions, most relevant to deal with firms' investment decisions and the execution of their financial strategy. Custódio and Metzger (2014) concludes that having a background in finance matters for corporate performance and particularly for firm financial management. Güner et al. (2008) suggests that financial expert CEOs have better access to external financing and have lower investment-cash flow sensitivity. 
Another variable of functional background is given by former experience in international foreign-owned firms, IntExpManager. Foreign-owned firms are defined as those with more than 50 percent of their total equity belonging to foreign capital, which includes all multinational companies and multinational enterprise subsidiaries. Finally, we will also consider managers' former export experience, ExportExpManager, given by the average years of managerial experience obtained in exporting firms, which we define as firms with an exports-to-sales ratio superior to the national average during three consecutive years - see Berthou et al. (2015) for alternative measures of exporting firms. Mion and Opromolla (2014) conclude that managers' export experience is an important determinant of firms' performance.

In respect to firm-level financial and performance indicators we consider three controls: i) Leverage, LevRatio, given by the ratio of liabilities to total equity and liabilities; ii) Productivity, Productivity, measured by the gross value-added in thousands of euros per worker; iii) Exports-to-sales ratio, ExportsRatio, a measure on firms' export capacity computed as the share of total exports over total sales.

All the variables used in our empirical analysis are presented and described in Table 1 .

\subsection{Management features, firms' financial condition and size}

Given the focus of our analysis, Table 2 presents the averages for the full sample (Panel A) and the subsamples of non-financially distressed firms (non-FDF) (Panel B) and financially distressed firms (Panel C), for the years 2011 and 2018 and for the four firm-size classes considered in our empirical analysis.

Management teams' characteristics show a significant variation across different firmsize classes. The human capital variables considered in our analysis increase monotonically with firm-size. For example, in 2018, differences in average years of schooling, EducManager, ranged from 10 years in micro firms, 11.2 in small firms, 13.2 in medium firms to 14.5 in large firms - see columns 2, 4, 6 and 8 in Panel A in Table 2. The percentage of management teams that include a member with a college degree, CollegeManager, is also much lower in micro and small-sized firms than in medium and large-sized firms. For example, in 2018, 25.6\% and $47.9 \%$ of micro and small-sized 
firms, respectively, had a least one member in their management teams with a college degree, whereas those percentages were $82.5 \%$ and $96.8 \%$ for medium and large-sized firms, respectively - see Panel A in Table 2. These patterns apply to all measures of human capital considered in our analysis.

The variables on the management team education - EducManager, CollegeManager and ShareCollegeManager - show a significant improvement between 2011 and 2018, for all firm-size classes, both for non-FDF and FDF. These improvements in the education levels of management teams reflect the progress in education in Portugal in the last decades (e.g., Almeida et al., 2017).

Between 2011 and 2018, there was an increase in average years of schooling of managers, EducManager, from 10 to 10.6, an increase in the percentage of firms with at least one member in the management team with a college degree, CollegeManager, from $30.6 \%$ to $36 \%$, and an increase in share of the management team with a college degree, ShareCollegeManager, from $23.6 \%$ to $28.3 \%$ - see columns 9 and 10 of Panel A in Table 2.

Small and medium-sized firms show an increase in the share of managers with a college degree, ShareCollegeManager, around 5 and 6 percentage points, respectively - see columns 3, 4, 5 and 6 in Panel $\mathrm{A}$ in Table 2. On the other hand, micro firms show an increase of only 3 percentage points in the percentage of firms with at least one manager with a college degree and in the share of managers with a college degree - see columns 1 and 2 in Panel A in Table 2.

A striking result is that FDF seems to have improved management teams' formal education more than non-FDF. Considering the statistics for the aggregate in 2018, we contend that FDF management teams average education was 11.1 years (10.6 years for non-FDF); there were $42.9 \% \mathrm{FDF}$ with at least one manager with a college degree $(35.7 \%$ in non-FDF); FDF had a $33.5 \%$ share of managers with a college degree $(28 \%$ for non-FDF) - see Panels B and C in Table 2.

Between non-FDF and FDF, management teams' education also varies with the firm-size category. Small and medium FDF management teams show higher levels of education than their non-FDF counterparts. In 2018, average years of schooling of managers in small and medium FDF were, respectively, 12.3 and 14.1, whereas for non-FDF those values were 11.2 and 13.1 - see Panels B and C in Table 2. 
Table 2: Summary statistics for full sample, non-FDF and FDF by firm size $(2011-2018)$

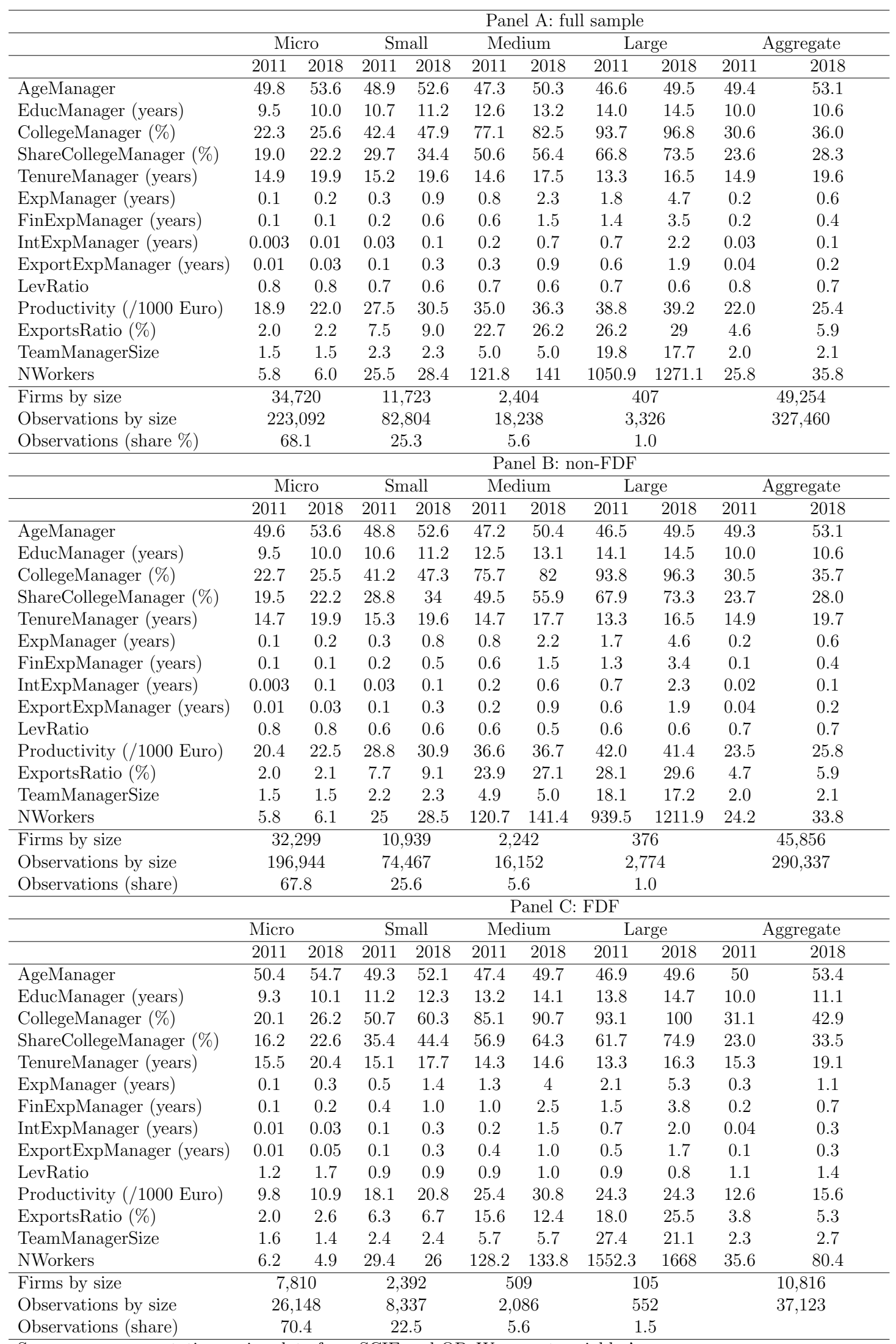

Source: own computations using data from SCIE and QP. We report variables' averages. 
Size also matters to differentiate between FDF and non-FDF in higher education measures. In small and medium FDF, in 2018, the relative weight of having at least one graduate member in the management team, CollegeManager, amounted to $60.3 \%$ and $90.7 \%$, respectively (ShareCollegeManager, $22.6 \%$ and $44.4 \%$ ), against $47.3 \%$ and $82 \%$ in those size categories for non-FDF (ShareCollegeManager, $22.2 \%$ and $34 \%$ ). Although departing from lower values in 2011, the presence of higher educated managers in micro FDF has noticeably improved, reaching 26.2\% in 2018, above nonFDF counterparts (25.5\%) - see Panels B and C in Table 2.

On tacit within-firm knowledge, the variable TenureManager increased, on average, in all size classes between 2011 and 2018, suggesting the steadiness of management teams in the same firm over time. Considering the year 2018, data on Panel A in Table 2 shows that tenure decreases monotonically with firm-size, ranging from 19.9 years in micro firms to 16.5 years in large firms. Except for medium-sized firms, this variable reported a similar trend between FDF and non-FDF - see Panels B and C of Table 2.

Regarding management teams' overall functional experience acquired in other firms, there was a significant improvement in all variables, between 2011 and 2018 - see Table 2. Micro firms stand out as showing a very small increase in management teams' human capital brought in by managers with previous experience in other firms. On the other hand, medium and large firms have increased substantially functional experience acquired in other firms, namely in the area of finance, FinExpManager, in foreignowned firms, IntExpManager, and in exporting firms, ExportExpManager.

In all size classes and particularly visible in medium and large firms, FDF management teams show higher experience in overall management, ExpManager, and in finance fields, FinExpManager, than non-FDF. Concerning experience in international foreign-owned firms, IntExpManager, and in exporting firms ExportExpManager, except for large firms, management teams in FDF show a higher average than in non-FDF - see Panels B and C in Table 2.

Table 2 also reports statistics for firms' financial and performance indicators, used as control variables in our estimations. From 2011 to 2018, these measures reveal an improvement in firms' financial conditions reflecting economic recovery after 2013. FDF exhibit higher leverage ratios, LevRatio, and lower labour productivity levels, Productivity, and export ratios, ExportsRatio, than their non-FDF counterparts - see 
Panels B and C in Table 2. This evidence is in line with existing literature on the topic - see, for example, Andrews et al. (2017).

Table 2 shows that productivity increases monotonically with firm-size. In 2018, it was $22,30.5,36.3$ and 39.2 thousand euro for micro, small, medium and large firms, respectively - see Panel A in Table 2. Between 2011 and 2018, productivity in the aggregate increased from 22 to 25.4 - see Panel A in Table 2. Productivity increased for micro, small and medium-sized non-FDF and FDF - see Panels B and C in Table 2. Overall, from 2011 to 2018 , it ranged from 23.5 to 25.8 in non-FDF and from 12.6 to 15.6 in FDF.

Non-FDF, except for micro firms, show a significant decrease in the leverage ratio, LevRatio, from 2011 to 2018. In turn, FDF except for large firms, show an increase in leverage on that period. It is in micro FDF where the leverage ratios have deteriorated more between 2011 and 2018, respectively from 1.2 to 1.7. Finally, the exports-tosales ratio, ExportsRatio, increased in all size classes of the whole sample - Panel A in Table 2, in the period 2011-2018, from $4.6 \%$ to $5.9 \%$. It reflects the increasing internationalization of Portuguese firms in the last decades. Except for medium-sized firms, the export ratio substantially increased in FDF, particularly in micro (from $2 \%$ to $2.6 \%$ ) and large firms (from $18 \%$ to $25.5 \%$ ).

\section{$3 \quad$ Econometric strategy}

The main hypotheses of this paper state that management teams' human capital in its different forms - formal education, within-firm specific knowledge, and functional experience formerly acquired in other firms - affect the likelihood of micro, small and medium-sized firms to become financially distressed and their odds of subsequent recovery. Therefore, our estimations aim at evaluating the following hypotheses:

i) Does management teams' human capital reduce the probability of financial distress, namely of micro and small-sized firms?

ii) For firms in a state of financial distress, does management teams' human capital increase the odds of recovery, namely of micro and small-sized firms?

iii) Does the impact of management teams' characteristics on the financial condition of firms vary across firm size? 
In order to test those hypotheses we make use of the longitudinal nature of the data, using a panel data logit estimator which accounts for firms' unobserved heterogeneity. We estimate by firm-size classes the following model:

$$
P\left(F D F_{i t}=1 \mid \mathbf{X}_{\mathbf{i t}}, \boldsymbol{\beta}, \alpha_{i}\right)=\frac{\exp \left(\boldsymbol{\beta} \mathbf{X}_{\mathbf{i t}}+\alpha_{i}\right)}{1+\exp \left(\boldsymbol{\beta} \mathbf{X}_{\mathbf{i t}}+\alpha_{i}\right)}
$$

where the dependent variable is the probability that firm $i$, in moment $t$, is financially distressed, $i=1, \ldots, N$ firms, $t=1, \ldots, T$ periods and $\alpha_{i}$ represents firms' (unobserved) heterogeneity. $\boldsymbol{X}_{i t}$ is the vector of all explanatory and control variables.

Concerning the explanatory variables, we consider three alternative measures of management teams' human capital. First, managers' formal education will be captured by three variables: EducManager, CollegeManager and ShareCollegeManager. Second, within-firm specific knowledge will be proxied by managers' tenure, TenureManager. Third, functional experience formerly acquired in other firms is measured by four variables: ExpManager, FinExpManager, IntExpManager and ExportExpManager. As control variables, we consider LevRatio, Productivity and ExportsRatio. All variables are included according to the definition presented in Table 1.

Firms' financial distress condition may be the result of previous decisions by management teams. Therefore, explanatory variables related to management teams are lagged one period. The inclusion of lagged independent variables also mitigates potential endogeneity issues.

We use an identical econometric procedure to evaluate the role of management teams' human capital on the odds of recovery of financially distressed firms, which is our second hypothesis. In this stage of our econometric strategy, the dependent variable is the probability of FDF to recover. Recovery status is defined by firms' interest coverage ratio bigger than one for at least two consecutive years, after its FDF status. The nonrecovery status includes firms that remained in a financially distressed condition plus all financially distressed firms that have exited the market in the following years. Given that registry is officially updated each year for any firm in our national datasets, the classification of exit is associated with the absence of registry of any given firm which was once registered. 
We use the results of the models described above, estimated for the four subsamples of our firm-size classes, to evaluate how the impact of the management team's human capital on the financial condition affects micro and small-sized firms and how it compares with medium and large-sized firms. This way, we test our third hypothesis.

Table A2, in the Appendix, presents the summary statistics for the variables used in our empirical analysis.

\section{Results}

\subsection{Probability of financial distress}

In this section we test the first and the third hypotheses of our paper, that is, we investigate the role of management teams' human capital in reducing the probability of financial distress and how it varies with firm size. The results of the estimates of the Logit model specified in equation 1, in Section 3, for the four size-classes subsamples, are presented in Tables 3 and 4.

Table 3 presents the estimates for our three measures of formal education: managers' average years of schooling, EducManager, Panel A; a dummy variable indicating if at least one manager has a college degree, CollegeManager, Panel B; and the share of the management team that has a college degree, ShareCollegeManager, Panel C. In all models, we consider the variable TenureManager as a measure of within-firm specific knowledge.

The results presented in Table 3 show that the impact and the statistical significance of the management teams' formal education on the probability of firms becoming financially distressed depends on firm size and on the measure of formal education that we include in our estimations.

Except for large firms, higher average years of schooling, EducManager, reduces the probability of firms becoming financially distressed - see Panel A in Table 3. The impact of managers' education is stronger for micro and small firms, being statistically significant at the $1 \%$ level. For medium-sized firms, the effect is smaller and it is only statistically significant at the $10 \%$ level. The inclusion of at least one manager with a college degree in the management team, CollegeManager, is only relevant for micro 
Table 3: Estimation results by firm size on Probability of FDF (2011 - 2018)

\begin{tabular}{|c|c|c|c|c|}
\hline & Micro & Small & Medium & Large \\
\hline & \multicolumn{4}{|c|}{ Panel A } \\
\hline EducManager & $\begin{array}{c}-0.120^{* * *} \\
(0.015)\end{array}$ & $\begin{array}{c}-0.115^{* * *} \\
(0.021)\end{array}$ & $\begin{array}{c}-0.099^{*} \\
(0.056)\end{array}$ & $\begin{array}{l}-0.095 \\
(0.144)\end{array}$ \\
\hline \multirow[t]{2}{*}{ TenureManager } & $\begin{array}{c}-0.122^{* * *} \\
(0.005) \\
\end{array}$ & $\begin{array}{c}-0.046^{* * * *} \\
(0.007)\end{array}$ & $\begin{array}{c}-0.045^{* * *} \\
(0.014) \\
\end{array}$ & $\begin{array}{l}-0.046 \\
(0.038) \\
\end{array}$ \\
\hline & \multicolumn{4}{|c|}{ Panel B } \\
\hline CollegeManager & $\begin{array}{c}-0.004^{* * *} \\
(0.001)\end{array}$ & $\begin{array}{c}0.002 \\
(0.001)\end{array}$ & $\begin{array}{c}0.002 \\
(0.003)\end{array}$ & $\begin{array}{c}0.012 \\
(0.009)\end{array}$ \\
\hline \multirow[t]{2}{*}{ TenureManager } & $\begin{array}{c}-0.120^{* * *} \\
(0.005)\end{array}$ & $\begin{array}{c}-0.036^{* * *} \\
(0.007)\end{array}$ & $\begin{array}{c}-0.033^{* *} \\
(0.013)\end{array}$ & $\begin{array}{l}-0.049 \\
(0.039)\end{array}$ \\
\hline & \multicolumn{4}{|c|}{ Panel C } \\
\hline ShareCollegeManager & $\begin{array}{c}-0.009^{* * *} \\
(0.001)\end{array}$ & $\begin{array}{c}-0.006^{* * *} \\
(0.002)\end{array}$ & $\begin{array}{l}-0.003 \\
(0.004)\end{array}$ & $\begin{array}{l}-0.001 \\
(0.009)\end{array}$ \\
\hline TenureManager & $\begin{array}{c}-0.121^{* * *} \\
(0.005)\end{array}$ & $\begin{array}{c}-0.042^{* * *} \\
(0.007)\end{array}$ & $\begin{array}{c}-0.039^{* * *} \\
(0.014)\end{array}$ & $\begin{array}{l}-0.045 \\
(0.038)\end{array}$ \\
\hline \multicolumn{5}{|c|}{$\begin{array}{l}\text { Notes: standard errors in parenthesis. Significance levels: }{ }^{*}, 10 \% ; * *, \\
5 \% \text {; } * * *, 1 \% \text {. Size: Micro firms }<10 \text { workers; } 10 \leq \text { Small firms }<50 \\
\text { workers; } 50 \leq \text { Medium firms }<250 \text { workers; Large firms } \geq 250 \text { workers. } \\
\text { Observations report only to firms with varying outcome. The number of } \\
\text { observations for Micro, Small, Medium and Large firms is } 32,170,9,452 \text {, } \\
2,130 \text { and } 538 \text {, respectively; the number of firms included in each one of } \\
\text { these estimations is } 4,594,1,339,293 \text { and } 70 \text {, respectively. Source: own } \\
\text { computations using data from SCIE and QP. }\end{array}$} \\
\hline
\end{tabular}

firms, being statistically significant at the $1 \%$ level - see Panel B in Table 3. Finally, concerning the impact of our third measure of formal education, the share of managers with a college degree, ShareCollegeManager, on the reduction of the probability of the firm becoming financially distressed is only relevant for micro and small firms, being statistically significant at the $1 \%$ level - see Panel C in Table 3.

The results for the subsample of large firms are statistically non-significant for all kinds of formal education - see column four in Table 3. These results may be explained by the small number of large firms in the sample (70) and the fact that the management teams of these firms have a very high level of education - see Table 2.

In what concerns our second category of managerial human capital, TenureManager, which measures tacit firm-specific knowledge, our results presented in Table 3 show that, except for large firms, a more experienced management team with better knowledge of 
inner processes and the firm's business model, reduces the probability of financial distress, partially verifying the findings of Huang and Hilary (2018). The effect is stronger for micro firms than for small and medium firms, being highly statistically significant for those three firm-size categories.

Summing-up, the results presented in Table 3 show that the three measures of the management teams' formal education and firm-specific knowledge reduce the probability of micro, small and medium-sized firms becoming financially distressed. Those results also suggest that the impact of both forms of management teams' human capital on firms' financial condition decreases monotonically with firm size.

The estimations presented in Table 4 consider managers' years of schooling as the measure of formal education, EducManager, and four indicators of management teams' functional experience acquired in other firms: managers' years of previous experience in other firms, ExpManager; previous experience in the area of finance, FinExpManager; previous experience in international firms, IntExpManager; and years of experience in former exporting firms, ExporExpManager.

Our results suggest that the four measures of functional experience previously acquired in other firms are relevant to reduce the probability of micro firms being financially distressed. However, some of the variables that measure functional experience are also relevant for small and medium-sized firms. The results, in Panel A, show that management experience accumulated in other firms, ExpManager, seems to be relevant to micro and medium-sized firms. Variable FinExpManager is statistically significant at the $10 \%$ and the $5 \%$ level for micro and medium-sized firms, respectively, while being statistically non-significant for small and large firms - see Panel B in Table 4. To have members in the management board with former experience in foreign-owned firms, IntExpManager, seems to be relevant for micro and small-sized firms to avoid becoming financially distressed - see Panel $\mathrm{C}$ in Table 4. These results complement Li (2018), who conclude that managers' international experience has a positive effect on firms' trade performance. Finally, having higher previous experience in firms involved in international trade, ExportExpManager, also reduces the likelihood of small-sized firms being financially distressed, which adds to the findings of Mion and Opromolla (2014) - see Panel D in Table 4.

All control variables included in the model show the expected effect on the proba- 
Table 4: Estimation results by firm size on the probability of FDF (2011 - 2018)

\begin{tabular}{lcccc}
\hline & Micro & Small & Medium & Large \\
\hline EducManager & $-0.057^{* * *}$ & $-0.077^{* * *}$ & -0.005 & -0.065 \\
& $(0.014)$ & $(0.021)$ & $(0.052)$ & $(0.144)$ \\
ExpManager & $-0.063^{* *}$ & -0.039 & $-0.119^{* * *}$ & -0.051 \\
& $(0.027)$ & $(0.024)$ & $(0.028)$ & $(0.047)$ \\
\hline EducManager & $-0.058^{* * *}$ & $-0.079^{* * *}$ & -0.008 & -0.076 \\
& $(0.014)$ & $(0.021)$ & $(0.052)$ & $(0.142)$ \\
FinExpManager & $-0.070^{*}$ & -0.012 & $-0.092^{* *}$ & -0.079 \\
& $(0.041)$ & $(0.030)$ & $(0.037)$ & $(0.057)$ \\
\hline \multirow{5}{*}{ Panel C } \\
\hline EducManager & $-0.059^{* * *}-0.076^{* * *}-0.026$ & -0.076 \\
& $(0.014)$ & $(0.021)$ & $(0.051)$ & $(0.143)$ \\
IntExpManager & $-0.464^{* *}$ & $-0.201^{* * *}$ & -0.017 & -0.112 \\
& $(0.212)$ & $(0.072)$ & $(0.049)$ & $(0.073)$ \\
\hline \multicolumn{5}{c}{ Panel D } \\
\hline EducManager & $-0.058^{* * *}-0.079^{* * *}$ & -0.020 \\
& $(0.014)$ & $(0.021)$ & $(0.051)$ & $(0.142)$ \\
ExportExpManager & $-0.276^{* *}$ & -0.064 & -0.059 & -0.102 \\
& $(0.116)$ & $(0.053)$ & $(0.050)$ & $(0.074)$ \\
\hline
\end{tabular}

Notes: standard errors in parenthesis. Significance levels: *, 10\%; $* *, 5 \%$; ***, $1 \%$. Size: Micro firms $<10$ workers; $10 \leq$ Small firms $<50$ workers; $50 \leq$ Medium firms $<250$ workers; Large firms $\geq 250$ workers. Observations report only to firms with varying outcome. The number of observations for Micro, Small, Medium and Large firms is $32,154,9,452,2,130$ and 538, respectively; the number of firms included in each one of these estimations is 4,592, 1,339, 293 and 70, respectively. Source: own computations using data from SCIE and QP.

bility of firms being financially distressed: lower debt or leverage ratios, higher productivity levels and exportation capacity help prevent firms from financial distress.

\subsection{Recovery of financially distressed firms}

In this section we investigate the impact of management teams' human capital on the odds of recovery of financially distressed firms, that is the second hypothesis we test 
in this study. We also gauge the variation of that impact across firm sizes, that is the third hypothesis to be tested.

As described in Section 3, we classify a firm as recovered from a condition of financial distress when the interest coverage ratio is bigger than one for two consecutive years. Table A3, in the Appendix, presents data for the number of firms that recovered from a condition of financial distress since 2010. Table A4, in the Appendix, presents the summary statistics of management teams' human capital by firm size, for recovered and non-recovered FDF, for the years 2011 and 2017. When compared to nonRecovered FDF firms, recovered FDF show a lower relative weight of higher educated managers in management boards, reported by the dummy variable of CollegeManager and ShareCollegeManager in Table A4. This evidence suggests that non-recovered FDF retain a considerable share of the highly qualified managerial workforce in their directorates, which supports the findings in literature characterizing the importance of factor misallocation in financially distressed firms and less productive organizations (e.g., Gouveia et al., 2018; McGowan et al., 2017; Gopinath et al., 2017). Additionally, managers of recovered FDF are more tenured and show slightly higher overall management, finance, international and exporting experience, features that turn out to play an important role in firms' financial performance.

Results presented in Tables 5 and 6, confirm the relevance of managerial human capital, namely formal education, within-firm specific knowledge, and functional experience of the management team acquired in other firms, to the recovery of financially distressed firms.

Table 5 presents the estimations of the impact of management teams' formal education and tenure in the recovery of financially distressed firms. The three measures of formal education - EducManager, CollegeManager and ShareCollegeManager suggest that more educated management teams increase the likelihood of recovery of micro, small and medium-sized financially distressed firms. In these size categories, the measures of formal education EducManager and ShareCollegeManager are statistically significant at the $1 \%$ level - see Panels A and C in Table 5. Having at least a manager with a college degree, CollegeManager, is only statistically significant for micro and small-sized firms. It should be stressed that the magnitude of the effect of formal education is higher for micro and small-sized financially distressed firms. 
Table 5: Estimation results by Firms' Size on Probability of Recovery (2011 - 2017)

\begin{tabular}{lcccc}
\hline & Micro & Small & Medium & Large \\
\hline EducManager & $0.618^{* * *}$ & $0.459^{* * *}$ & $0.470^{* * *}$ & 0.289 \\
& $(0.033)$ & $(0.041)$ & $(0.096)$ & $(0.208)$ \\
TenureManager & $0.549^{* * *}$ & $0.202^{* * *}$ & $0.124^{* * *}$ & $0.148^{*}$ \\
& $(0.012)$ & $(0.014)$ & $(0.023)$ & $(0.082)$ \\
\hline CollegeManager & $0.022^{* * *}$ & $0.005^{* *}$ & 0.002 & 0.000 \\
& $(0.002)$ & $(0.002)$ & $(0.005)$ & $(0.011)$ \\
TenureManager & $0.525^{* * *}$ & $0.154^{* * *}$ & $0.072^{* * *}$ & $0.143^{*}$ \\
& $(0.012)$ & $(0.013)$ & $(0.020)$ & $(0.079)$ \\
& & \multicolumn{3}{c}{ Panel C } \\
\hline ShareCollegeManager & $0.062^{* * *}$ & $0.029^{* * *}$ & $0.020^{* * *}$ & 0.015 \\
& $(0.004)$ & $(0.003)$ & $(0.006)$ & $(0.015)$ \\
TenureManager & $0.542^{* * *}$ & $0.183^{* * *}$ & $0.098^{* * *}$ & $0.132^{*}$ \\
& $(0.012)$ & $(0.013)$ & $(0.021)$ & $(0.080)$ \\
\hline
\end{tabular}

Notes: standard errors in parenthesis. Significance levels: *, 10\%; $* *, 5 \%$; ***, $1 \%$. Size: Micro firms $<10$ workers; $10 \leq$ Small firms $<50$ workers; $50 \leq$ Medium firms $<250$ workers; Large firms $\geq 250$ workers. Observations report only to firms with varying outcome. The number of observations for Micro, Small, Medium and Large firms is $16,787,4,576,1,055$ and 186 , respectively; the number of firms included in each one of these estimations is 2,951, 795, 177 and 29, respectively. Source: own computations using data from SCIE and QP.

In what concerns our second category of managerial human capital, TenureManager, that measures within firm-specific knowledge, our results show that a more experienced management team, with a better knowledge of the firm and of its business model, increases the likelihood of the firm to recover from financial distress - see Table 5. Except for large firms, the effect of TenureManager is statistically significant at the $1 \%$ level. It should also be stressed that the effect is stronger for micro and small firms, highly reliant on tacit knowledge.

Finally, in Table 6, we present the estimates of the impact of functional experience previously acquired in other firms on the probability of firms' recovery from a condition of financial distress. Our results suggest that the four variables considered in our analysis - ExpManager, FinExpManager, IntExpManager and ExportExpManager 
Table 6: Estimation results by Firms' Size on Probability of Recovery (2011 - 2017)

\begin{tabular}{lcccc}
\hline & Micro & Small & Medium & Large \\
\hline EducManager & $0.195^{* * *}$ & $0.230^{* * *}$ & $0.177^{* *}$ & $0.484^{* *}$ \\
& $(0.022)$ & $(0.034)$ & $(0.084)$ & $(0.231)$ \\
ExpManager & $0.270^{* * *}$ & $0.235^{* * *}$ & $0.263^{* * *}$ & $0.739^{* * *}$ \\
& $(0.053)$ & $(0.045)$ & $(0.047)$ & $(0.195)$ \\
\hline EducManager & $0.198^{* * *}$ & $0.229^{* * *}$ & $0.181^{* *}$ & $0.556^{* *}$ \\
& $(0.022)$ & $(0.034)$ & $(0.082)$ & $(0.223)$ \\
FinExpManager & $0.293^{* * *}$ & $0.209^{* * *}$ & $0.168^{* * *}$ & $0.786^{* * *}$ \\
& $(0.072)$ & $(0.053)$ & $(0.056)$ & $(0.196)$ \\
\hline \multicolumn{5}{c}{ Panel C } \\
\hline EducManager & $0.200^{* * *}$ & $0.234^{* * *}$ & $0.211^{* * *}$ & 0.332 \\
& $(0.022)$ & $(0.034)$ & $(0.081)$ & $(0.213)$ \\
IntExpManager & $0.758^{* *}$ & $0.487^{* * *}$ & $0.138^{*}$ & 0.179 \\
& $(0.345)$ & $(0.137)$ & $(0.078)$ & $(0.171)$ \\
\hline \multicolumn{5}{c}{ Panel D } \\
\hline EducManager & $0.197^{* * *}$ & $0.229^{* * *}$ & $0.201^{* *}$ & 0.342 \\
& $(0.022)$ & $(0.034)$ & $(0.081)$ & $(0.216)$ \\
ExportExpManager & $1.281^{* * *}$ & $0.398^{* * *}$ & $0.169^{* *}$ & $0.544^{* *}$ \\
& $(0.497)$ & $(0.122)$ & $(0.073)$ & $(0.273)$ \\
\hline
\end{tabular}

Notes: standard errors in parenthesis. Significance levels: *, 10\%; $* *, 5 \%$; ***, $1 \%$. Size: Micro firms $<10$ workers; $10 \leq$ Small firms $<50$ workers; $50 \leq$ Medium firms $<250$ workers; Large firms $\geq 250$ workers. Observations report only to firms with varying outcome. The number of observations for Micro, Small, Medium and Large firms is $16,787,4,576,1,055$ and 186, respectively; the number of firms included in each one of these estimations is 2,951, 795, 177 and 29, respectively. Source: own computations using data from SCIE and QP.

- increase the likelihood of recovery of micro and small-sized financially distressed firms, being statistically significant at the $1 \%$ level - see columns 1 and 2 in Table 6. Managers' prior experience in other companies, ExpManager, and former finance experience in other firms, FinExpManager, also increases the likelihood of recovery of medium and large-sized financially distressed firms, being statistically significant at the $1 \%$ level - see Panels A and B in Table 6. Previous experience in foreign-owned firms, IntExpManager, is also relevant to the recovery of medium-sized financially dis- 
tressed firms, but it is only statistically significant at the $10 \%$ level. Finally, previous experience in exporting firms, ExportExpManager, may as well help in the recovery of medium and large-sized financially distressed firms. The estimations presented in Table 6 also suggest that the impact of functional experience previously acquired either in foreign-owned or in exporting firms is stronger for micro and small-sized firms.

In what concerns the control variables, our results show that high-leveraged firms with higher exports-to-sales ratio have a higher probability of recovery. Additionally, firms with higher productivity also have a higher probability of recovery, confirming previous findings (e.g., Carreira and Teixeira, 2011).

\section{Conclusions}

The contribution of this paper is two-fold. On the one hand, it contributes to the literature on the determinants of firms' financial distress condition. Several authors have emphasized the role of leverage and credit constraints or the misallocation of resources that result from inefficient or underdeveloped financial markets. In this paper, we contribute to that literature by investigating the impact of management teams' human capital on the probability of firms becoming financially distressed.

On the other hand, the availability of linked employer-employee databases that include all the population of Portuguese firms, allows our analysis to be focused on micro and small-sized firms. Micro and small firms are pervasive in the business structure of the Portuguese economy, accounting for more than half to total employment and valueadded.

Our estimates show that management teams' formal education reduces the probability of firms becoming financially distressed and increase the odds of their subsequent recovery. However, our results also show that the relevance of management teams' human capital depends on firms' size and the type of education - average educational level and higher education. Namely, we show that management teams' formal education has a stronger and highly significant impact in reducing the probability of micro and small-sized firms becoming financially distressed and in increasing the chances of their subsequent recovery. We also conclude that functional experience previously acquired in other firms, namely in foreign-owned companies, exporting firms and in the 
area of finance, may reduce the probability of micro firms becoming financially distressed. Finally, previous functional experience in other firms seems to have a strong and highly significant impact in increasing the odds of recovery of financially distressed firms. Summing-up, our results suggest that Portuguese micro and small-sized firms could improve their financial performance by increasing management teams' human capital.

Despite significant improvements in the last decades, Portuguese firms' management teams still lag behind European Union education levels. These results suggest that policies that induce an improvement in the managerial human capital of micro and small-sized firms may contribute to a better financial condition, reducing the likelihood of firms entering a state of financial distress. Therefore, more educated management teams may contribute to enhance productivity and the resilience of the economy against shocks, such as the pandemic COVID-19.

\section{References}

Acharya, V. V., Eisert, T., Eufinger, C., and Hirsch, C. (2019). Whatever it takes: The real effects of unconventional monetary policy. The Review of Financial Studies, $32(9): 3366-3411$.

Almeida, A., Figueiredo, H., Cerejeira, J., Portela, M., Sá, C., and Teixeira, P. (2017). Returns to postgraduate education in portugal: Holding on to a higher ground? IZA Discussion Paper No. 10676.

Andrews, D., McGowan, M. A., and Millot, V. (2017). Confronting the zombies: Policies for productivity revival. OECD Economic Policy Papers No. 2017-21.

Andrews, D. and Petroulakis, F. (2019). Breaking the shackles: zombie firms, weak banks and depressed restructuring in europe. ECB Working Paper No. 2240-2019.

Azevedo, N., Mateus, M., Pina, Á., et al. (2018). Bank credit allocation and productivity: Stylised facts for portugal. Banco de Portugal Working Papers No. 2018-25.

Berthou, A., Dhyne, E., Bugamelli, M., Cazacu, A.-M., Demian, V., Harasztosi, P., Lalinsky, T., Meriküll, J., Oropallo, F., and Soares, A. C. (2015). Assessing European 
firms' exports and productivity distributions: The CompNet trade module. ECB Working Paper No. 2015-1788.

Bloom, N., Eifert, B., Mahajan, A., McKenzie, D., and Roberts, J. (2013). Does management matter? Evidence from India. The Quarterly Journal of Economics, 128(1):1-51.

Bloom, N., Sadun, R., and Van Reenen, J. (2016). Management as a technology? NBER Working Paper No. 22327.

Bloom, N. and Van Reenen, J. (2007). Measuring and explaining management practices across firms and countries. The Quarterly Journal of Economics, 122(4):1351-1408.

Bloom, N. and Van Reenen, J. (2010). Why do management practices differ across firms and countries? Journal of Economic Perspectives, 24(1):203-24.

Boone, A. L., Field, L. C., Karpoff, J. M., and Raheja, C. G. (2007). The determinants of corporate board size and composition: An empirical analysis. Journal of Financial Economics, 85(1):66-101.

Caballero, R. J., Hoshi, T., and Kashyap, A. K. (2008). Zombie lending and depressed restructuring in Japan. American Economic Review, 98(5):1943-77.

Carpenter, M. A. (2002). The implications of strategy and social context for the relationship between top management team heterogeneity and firm performance. Strategic Management Journal, 23(3):275-284.

Carreira, C. and Teixeira, P. (2011). The shadow of death: Analysing the pre-exit productivity of Portuguese manufacturing firms. Small Business Economics, 36(3):337351.

Carreira, C. and Teixeira, P. (2016). Entry and exit in severe recessions: Lessons from the 2008-2013 Portuguese economic crisis. Small Business Economics, 46(4):591-617.

Chen, H.-L., Hsu, W.-T., and Huang, Y.-S. (2010). Top management team characteristics, R\&D investment and capital structure in the IT industry. Small Business Economics, 35(3):319-333. 
Custódio, C. and Metzger, D. (2014). Financial expert CEOs: CEO's work experience and firm's financial policies. Journal of Financial Economics, 114(1):125-154.

Darrat, A. F., Gray, S., Park, J. C., and Wu, Y. (2016). Corporate governance and bankruptcy risk. Journal of Accounting, Auditing \& Finance, 31(2):163-202.

Fukuda, S.-i. and Nakamura, J.-i. (2011). Why did 'zombie'firms recover in Japan? The World Economy, 34(7):1124-1137.

Garicano, L., Lelarge, C., and Van Reenen, J. (2016). Firm size distortions and the productivity distribution: Evidence from France. American Economic Review, 106(11):3439-79.

Gopinath, G., Kalemli-Ozcan, S., Karabarbounis, L., and Villegas-Sanchez, C. (2017). Capital allocation and productivity in south Europe. The Quarterly Journal of Economics, 132(4):1915-1967.

Gouveia, A. F., Osterhold, C., et al. (2018). Fear the walking dead: Zombie firms, spillovers and exit barriers. OECD Productivity Working Papers No. 13-2018.

Güner, A. B., Malmendier, U., and Tate, G. (2008). Financial expertise of directors. Journal of Financial Economics, 88(2):323-354.

Hambrick, D. C. and Mason, P. A. (1984). Upper echelons: The organization as a reflection of its top managers. Academy of Management Review, 9(2):193-206.

Huang, S. and Hilary, G. (2018). Zombie board: Board tenure and firm performance. Journal of Accounting Research, 56(4):1285-1329.

INE, S. P. (2018a). Quadros de Pessoal. Instituto Nacional de Estatística, Lisboa.

INE, S. P. (2018b). Sistema de Contas Integradas das Empresas. Instituto Nacional de Estatística, Lisboa.

Li, P.-Y. (2018). Top management team characteristics and firm internationalization: The moderating role of the size of middle managers. International Business Review, $27(1): 125-138$. 
Lin, H.-C. and Lin, P.-C. (2019). The interplay between CEO-TMT exchange level and differentiation: Implications for firm competitive behaviors and performance. Journal of Business Research, 95:171-181.

Lucas, R. E. (1978). On the size distribution of business firms. The Bell Journal of Economics, 9(2):508-523.

McGowan, M. A., Andrews, D., and Millot, V. (2017). The walking dead? Zombie firms and productivity performance in OECD countries. OECD Economic Department Working Papers No. 1372.

Mion, G. and Opromolla, L. D. (2014). Managers' mobility, trade performance, and wages. Journal of International Economics, 94(1):85-101.

Mion, G., Opromolla, L. D., and Sforza, A. (2016). The diffusion of knowledge via managers' mobility. CEPR Discussion Paper No. DP11706.

Reis, R. (2013). The Portuguese slump and crash and the euro crisis. Brookings Papers on Economic Activity, 46(1):143-210.

Roos, J., Edvinsson, L., and Dragonetti, N. C. (1997). Intellectual capital: Navigating the new business landscape. Springer.

Sazedj, S., Amador, J., and Tavares, J. (2018). CEO performance in severe crises: The role of newcomers. CEPR Discussion Paper No. DP13294-2018.

Schivardi, F., Sette, E., and Tabellini, G. (2017). Credit misallocation during the European financial crisis. Bank of Italy Temi di Discussione Working Paper No. 1139. 


\section{Appendix}

Table A1: Summary statistics by firm size $(2011-2018)$

\begin{tabular}{|c|c|c|c|c|c|c|c|c|c|c|}
\hline & \multicolumn{2}{|c|}{ Micro } & \multicolumn{2}{|c|}{ Small } & \multicolumn{2}{|c|}{ Medium } & \multicolumn{2}{|c|}{ Large } & \multicolumn{2}{|c|}{ Aggregate } \\
\hline & 2011 & 2018 & 2011 & 2018 & 2011 & 2018 & 2011 & 2018 & 2011 & 2018 \\
\hline & \multicolumn{10}{|c|}{ Sample } \\
\hline Firms & 30,969 & 18,477 & 10,718 & 7,611 & 2,253 & 1,793 & 396 & 339 & 44,336 & 28,220 \\
\hline NWorkers & 181,045 & 111,032 & 273,768 & 216,384 & 274,307 & 252,787 & 416,163 & 430,889 & $1,145,283$ & $1,011,092$ \\
\hline Firms (\% total) & 69.85 & 65.47 & 24.17 & 26.97 & 5.08 & 6.35 & .89 & 1.2 & & \\
\hline NWorkers (\% total) & 15.81 & 10.98 & 23.9 & 21.4 & 23.95 & 25 & 36.34 & 42.62 & & \\
\hline Firms & 324,336 & 376,719 & 31,246 & 31,876 & 4,699 & 4,488 & 713 & 684 & 360,994 & 413,767 \\
\hline NWorkers & 877,013 & 957,551 & 667,437 & 763,734 & 495,932 & 564,599 & 624,719 & 707,378 & $2,665,101$ & $2,993,262$ \\
\hline Firms (\% total) & 89.9 & 91.1 & 8.7 & 7.7 & 1.3 & 1.1 & 0.2 & 0.2 & & \\
\hline NWorkers (\% total) & 32.9 & 32.0 & 25.0 & 25.5 & 18.6 & 18.9 & 23.4 & 23.6 & & \\
\hline Value-added ( $\%$ total) & 24.2 & 26.7 & 22.4 & 23.6 & 22.2 & 21.8 & 31.2 & 27.9 & & \\
\hline
\end{tabular}

Source: own computations using data from SCIE.

Table A2: Summary statistics (2018)

\begin{tabular}{lccccccc}
\hline & Mean & Std.dev. & Perc. 1 & Median & Perc. 99 & Min & Max \\
\hline FDF & 0.04 & 0.20 & 0 & 0 & 1 & 0 & 1 \\
AgeManager & 53.11 & 7.68 & 35 & 53 & 68 & 20 & 68 \\
EducManager & 10.58 & 3.98 & 4 & 11 & 17 & 4 & 20 \\
CollegeManager & 36.05 & 48.01 & 0 & 0 & 100 & 0 & 100 \\
ShareCollegeManager & 28.28 & 40.89 & 0 & 0 & 100 & 0 & 100 \\
TenureManager & 19.65 & 8.05 & 0 & 20 & 40 & 0 & 59 \\
ExpManager & 0.58 & 1.94 & 0 & 0 & 11 & 0 & 13 \\
FinExpManager & 0.38 & 1.45 & 0 & 0 & 8 & 0 & 13 \\
IntExpManager & 0.11 & 0.86 & 0 & 0 & 5 & 0 & 13 \\
ExportExpManager & 0.17 & 1.05 & 0 & 0 & 6 & 0 & 13 \\
LevRatio & 0.75 & 1.22 & 0 & 1 & 8 & 0 & 11 \\
Productivity & 25.40 & 22.73 & -4 & 20 & 134 & -25 & 179 \\
ExportsRatio & 5.86 & 18.49 & 0 & 0 & 95 & 0 & 100 \\
TeamManagerSizes & 2.11 & 4.84 & 1 & 2 & 11 & 1 & 419 \\
NWorkers & 35.83 & 311.72 & 2 & 8 & 421 & 2 & 26,857 \\
\hline \hline
\end{tabular}

Source: own computations using data from SCIE and QP. The number of observations is 28,220. 'Std.dev.' stands for standard deviation; 'Perc.' stands for percentile. 
Table A3: Evolution of recovered FDF (2011 - 2017)

\begin{tabular}{lcccc}
\hline & non-Recovered & Recovered & Aggregate & Share recovered (\%) \\
\hline 2011 & 6,457 & 548 & 7,005 & 7.8 \\
2012 & 6,280 & 890 & 7,170 & 12.4 \\
2013 & 5,458 & 1,359 & 6,817 & 19.9 \\
2014 & 4,508 & 2,013 & 6,521 & 30.9 \\
2015 & 3,452 & 2,694 & 6,146 & 43.8 \\
2016 & 2,648 & 3,219 & 5,867 & 54.9 \\
2017 & 1,828 & 3,568 & 5,396 & 66.1 \\
\hline Firms & 10,944 & 4,509 & 10,946 & 41.2 \\
Observations & 36,963 & 14,291 & 51,254 & 27.9 \\
\hline
\end{tabular}

Source: own computations using data from SCIE and QP.

Table A4: Summary statistics for non-Recovered and Recovered FDF by firm size (2011 - 2017)

\begin{tabular}{|c|c|c|c|c|c|c|c|c|c|c|}
\hline & \multicolumn{10}{|c|}{ Panel A: non-Recovered } \\
\hline & \multicolumn{2}{|c|}{ Micro } & \multicolumn{2}{|c|}{ Small } & \multicolumn{2}{|c|}{ Medium } & \multicolumn{2}{|c|}{ Large } & \multicolumn{2}{|c|}{ Aggregate } \\
\hline & 2011 & 2017 & 2011 & 2017 & 2011 & 2017 & 2011 & 2017 & 2011 & 2017 \\
\hline AgeManager & 50.4 & 54.1 & 49.3 & 51.9 & 47.5 & 49.2 & 46.7 & 49.4 & 50.0 & 53.1 \\
\hline EducManager & 9.3 & 9.9 & 11.2 & 12.1 & 13.2 & 13.8 & 13.9 & 14.6 & 9.9 & 10.9 \\
\hline CollegeManager & 19.8 & 24.2 & 50.9 & 56.8 & 85.0 & 87.0 & 94.3 & 100 & 30.4 & 39.0 \\
\hline ShareCollegeManager & 15.9 & 20.9 & 35.6 & 42.1 & 57 & 61.3 & 62.5 & 74.4 & 22.6 & 30.6 \\
\hline TenureManager & 15.4 & 19.9 & 15.1 & 18 & 14.3 & 14.8 & 13.3 & 16.3 & 15.3 & 18.9 \\
\hline ExpManager & 0.1 & 0.3 & 0.5 & 1.1 & 1.3 & 3.3 & 2.2 & 4.9 & 0.3 & 0.8 \\
\hline FinExpManager & 0.1 & 0.2 & 0.4 & 0.8 & 1.0 & 2.2 & 1.5 & 3.4 & 0.2 & 0.6 \\
\hline IntExpManager & 0.003 & 0.01 & 0.1 & 0.2 & 0.2 & 1.2 & 0.7 & 2.4 & 0.03 & 0.2 \\
\hline ExportExpManager & 0.01 & 0.02 & 0.1 & 0.2 & 0.4 & 0.9 & 0.5 & 1.5 & 0.1 & 0.2 \\
\hline LevRatio & 1.3 & 1.8 & 0.9 & 1.0 & 0.9 & 0.9 & 0.9 & 0.8 & 1.2 & 1.5 \\
\hline Productivity & 9.0 & 9.1 & 17.8 & 20.4 & 24.8 & 28.2 & 24.7 & 23.7 & 11.8 & 13.7 \\
\hline ExportsRatio & 1.9 & 2.5 & 6.2 & 7.5 & 15.7 & 17.6 & 18.5 & 21.7 & 3.7 & 5.4 \\
\hline TeamManagerSize & 1.6 & 1.5 & 2.4 & 2.3 & 5.7 & 5.1 & 28 & 29.7 & 2.2 & 2.8 \\
\hline NWorkers & 6 & 5 & 29.3 & 26 & 128.4 & 126.6 & 1573.1 & 2099.7 & 34.1 & 81.1 \\
\hline Firms by size & 7,9 & & 2, & 72 & 50 & & & & & 44 \\
\hline Observations by size & 26 & 463 & & 24 & 1,9 & 72 & & & & \\
\hline \multirow[t]{4}{*}{ Observations share (\%) } & 71 & & & .7 & 5 & & & & & \\
\hline & \multicolumn{10}{|c|}{ Panel B: Recovered } \\
\hline & \multicolumn{2}{|c|}{ Micro } & \multicolumn{2}{|c|}{ Small } & \multicolumn{2}{|c|}{ Medium } & \multicolumn{2}{|c|}{ Large } & \multicolumn{2}{|c|}{ Aggregate } \\
\hline & 2011 & 2017 & 2011 & 2017 & 2011 & 2017 & 2011 & 2017 & 2011 & 2017 \\
\hline AgeManager & 50.2 & 53.3 & 50.1 & 52.1 & 47.4 & 49.7 & 40.1 & 49.3 & 50.1 & 52.8 \\
\hline EducManager & 9.1 & 9.4 & 10.4 & 11.5 & 12.8 & 13.7 & 14.8 & 14.3 & 9.4 & 10.1 \\
\hline CollegeManager & 16.2 & 19.6 & 42.1 & 50 & 85.7 & 87.1 & 100 & 96.6 & 21.7 & 29.7 \\
\hline ShareCollegeManager & 14.3 & 16.6 & 31.6 & 36.7 & 50.7 & 61.9 & 71.4 & 65.8 & 17.7 & 23.3 \\
\hline TenureManager & 14.4 & 19.5 & 16 & 18.4 & 13.7 & 16.1 & 8.4 & 15.7 & 14.6 & 19.1 \\
\hline ExpManager & 0.1 & 0.2 & 0.4 & 0.9 & 1.4 & 2.9 & 2.0 & 4.5 & 0.2 & 0.5 \\
\hline FinExpManager & 0.1 & 0.1 & 0.2 & 0.7 & 0.7 & 1.9 & 4.0 & 3.4 & 0.1 & 0.3 \\
\hline IntExpManager & 0.01 & 0.01 & 0.06 & 0.2 & 0.3 & 0.6 & 4.0 & 1.7 & 0.03 & 0.1 \\
\hline ExportExpManager & 0.01 & 0.02 & 0.1 & 0.2 & 0.1 & 0.9 & 0.3 & 1.6 & 0.03 & 0.1 \\
\hline LevRatio & 2.1 & 1.5 & 1.2 & 0.8 & 0.8 & 0.8 & 0.9 & 0.7 & 1.9 & 1.3 \\
\hline Productivity & 12.1 & 16.4 & 19.1 & 24.3 & 30.0 & 32.0 & 35.3 & 30.7 & 13.6 & 18.9 \\
\hline ExportsRatio & 2.4 & 1.8 & 10.5 & 7.9 & 37 & 20.5 & 0.1 & 24.1 & 4.4 & 4.2 \\
\hline TeamManagerSize & 1.4 & 1.5 & 1.7 & 2.2 & 7.6 & 5.5 & 21.0 & 15.3 & 1.7 & 1.9 \\
\hline NWorkers & 4.7 & 5.3 & 24.2 & 25.6 & 110.6 & 136.4 & 777 & 1773.3 & 11.5 & 30.1 \\
\hline Firms by size & \multicolumn{2}{|c|}{3,413} & \multicolumn{2}{|c|}{874} & \multicolumn{2}{|c|}{192} & \multicolumn{2}{|c|}{30} & \multicolumn{2}{|c|}{4,509} \\
\hline Observations by size & \multicolumn{2}{|c|}{10,728} & \multicolumn{2}{|c|}{2,813} & \multicolumn{2}{|c|}{644} & \multicolumn{2}{|c|}{106} & \multicolumn{2}{|c|}{14,291} \\
\hline Observations share (\%) & \multicolumn{2}{|c|}{75.1} & 19 & & 4 & & & & & \\
\hline
\end{tabular}

Source: own computations using data from SCIE and QP. 


\section{Most Recent Working Paper}

NIPE WP $\quad$ Alexandre, F., Cruz, S., \& Portela, M. (2020). Financial distress and the role of management in

06/2020 micro and small-sized firms, 2020

NIPE WP Cooke, D., Ana P. Fernandes and Priscila Ferreira, Entry Deregulation, Firm Organization and

05/2020 Wage Inequality, 2020

NIPE WP Fernando Alexandre, Pedro Bação, João Cerejeira, Hélder Costa and Miguel Portela,

04/2020 Minimum wage and financially distressed firms: another one bites the dust, 2020

NIPE WP Luís Sá and Odd Rune Straume, Quality provision in hospital markets with demand inertia:

03/2020 The role of patient expectations, 2020

NIPE WP Rosa-Branca Esteves, Liu Qihong and Shuai, J., Behavior-Based Price Discrimination with Non-

02/2020 Uniform Distribution of Consumer Preferences, 2020

NIPE WP Diogo Teixeira and J. Cadima Ribeiro, "Residents' perceptions of the tourism impacts on a

01/2020 mature destination: the case of Madeira Island", 2020

NIPE WP Liao, R. C., Loureiro, G., and Taboada, A. G., "Women on Bank Boards: Evidence from Gender

17/2019 Quotas around the World", 2019

NIPE WP Luís Sá, "Hospital Competition Under Patient Inertia: Do Switching Costs Stimulate Quality

16/2019 Provision?”, 2019

NIPE WP João Martins and Linda G. Veiga, “Undergraduate students' economic literacy, knowledge of

15/2019 the country's economic performance and opinions regarding appropriate economic policies", 2019

NIPE WP Natália P. Monteiro, Odd Rune Straume and Marieta Valente, "Does remote work improve or

14/2019 impair firm labour productivity? Longitudinal evidence from Portugal", 2019

NIPE WP Luís Aguiar-Conraria, Manuel M. F. Martins and Maria Joana Soares, “ $\underline{\text { Okun's Law Across }}$

13/2019 Time and Frequencies", 2019

NIPE WP Bohn, F., and Veiga, F. J., "Political Budget Forecast Cycles", 2019

$12 / 2019$

NIPE WP Ojo, M. O., Aguiar-Conraria, L. and Soares, M. J., "A A Time-Frequency Analysis of Sovereign

11/2019 Debt Contagion in Europe", 2019

NIPE WP Lommerud, K. E., Meland, F. and Straume, O. R., "International outsourcing and trade union

10/2019 (de-) centralization", 2019

NIPE WP Carvalho, Margarita and João Cerejeira, "Level Leverage decisions and manager

09/2019 characteristics",2019

NIPE WP Carvalho, Margarita and João Cerejeira, "Financialization, Corporate Governance and

08/2019 Employee Pay: A Firm Level Analysis", 2019

NIPE WP Carvalho, Margarita and João Cerejeira, "Mergers and Acquisitions and wage effects in the

07/2019 Portuguese banking sector", 2019

NIPE WP Bisceglia, Michele, Roberto Cellini, Luigi Siciliani and Odd Rune Straume, "Optimal 06/2019 dynamic volume-based price regulation", 2019

NIPE WP Hélia Costa and Linda Veiga, "Local labor impact of wind energy investment: an analysis of

05/2019 Portuguese municipalities", 2019

NIPE WP Luís Aguiar-Conraria, Manuel M. F. Martins and Maria Joana Soares, " The Phillips Curve at 04/2019 60: time for time and frequency", 2019

NIPE WP Luís Aguiar-Conraria, Pedro C. Magalhães and Christoph A. Vanberg, "What are the best 03/2019 quorum rules? A Laboratory Investigation", 2019

NIPE WP Ghandour, Ziad R., "Public-Private Competition in Regulated Markets", 2019

02/2019

NIPE WP

$01 / 2019$

NIPE WP

$21 / 2018$

NIPE WP

20/2018

Alexandre, Fernando, Pedro Bação and Miguel Portela, "A flatter life-cycle consumption profile", 2019

NIPE WP

$19 / 2018$

Veiga, Linda, Georgios Efthyvoulou and Atsuyoshi Morozumi, "Political Budget Cycles:

Conditioning Factors and New Evidence", 2018

Sá, Luís, Luigi Siciliani e Odd Rune Straume, "Dynamic Hospital Competition Under Rationing by Waiting Times", 2018

Brekke, Kurt R., Chiara Canta, Luigi Siciliani and Odd Rune Straume, "Hospital Competition in the National Health Service: Evidence from a Patient Choice Reform", 2018 